\title{
Spatial variability of soil fertility in a coconut based agro ecological unit in the sandy plains of Kerala, India
}

\section{Mini and Usha Mathew}

MEMBERS OF RESEARCH FORUM:

Corresponding author :

V. Mini, Onattukara Regional Agricultural Research Station

(K.A.U.), Kayamkulam

(Kerala) India

Email: minisvilas@gmail.com

Co-authors :

Usha Mathew, Department of Soil Science, College of Agriculture,

Vellayani, Thiruvananthapuaram (Kerala) India
Received : 30.04.2018; Revised : 08.05.2018; Accepted : 22.05.2018

\section{Summary}

The sandy plain region of Kerala comprises a unique agro ecological unit designated as Onattukara sandy plain (AEU 3). The main cropping system prevailing in this region is coconut based cropping system in the upland. In the existing perennial plantations like coconut, soil fertility evaluation will help to identify the existing crop nutrition related constraints for formulating suitable nutrient management strategies. Therefore, this study was conducted with the objectives of identifying and mapping the spatial distribution of soil nutrient deficiencies for site specific nutrient management. Soil samples from 200 geo referenced sites were analyzed for available macro and micro nutrients. The nutrient deficiency maps developed can be used for macro and micronutrient management to address steady decline in the yield of coconut in the region through balanced nutrition. Yield gap of coconut in Onattukara region is 207.69 per cent. Thematic maps showed low organic carbon status in 74.2 per cent, $\mathrm{P}$ in 0.6 per cent and $\mathrm{K}$ in 82.6 per cent area. $\mathrm{Ca}$ and $\mathrm{Mg}$ deficiency were observed in 96.8 per cent area and $\mathrm{S}$ deficiency in 8.6 per cent area. Fe and Mn were observed to be sufficient. Zinc was found to be deficient in 90.3 per cent, $\mathrm{Cu}$ in 73.5 per cent and B in 93.1 per cent area of this sandy tract.

Key words : Coconut, Constraints, GIS, Mapping, Sandy tract, Soil nutrient status

How to cite this article : Mini, V. and Mathew, Usha (2018). Spatial variability of soil fertility in a coconut based agro ecological unit in the sandy plains of Kerala, India. Asian J. Soil Sci., 13 (1) : 58-62 : DOI : 10.15740/HAS/AJSS/13.1/58-62. Copyright@ 2018: Hind Agri-Horticultural Society. 